\title{
Hardening mechanism of commercially pure Mg processed by high pressure torsion at room temperature
}

\author{
Xiao Guang Qiao ${ }^{1, *}$, Ya Wei Zhao ${ }^{1}$, Wei Min Gan ${ }^{2}$, Ying $\mathrm{Chen}^{3}$, Ming Yi Zheng ${ }^{1}$, Kun \\ $\mathrm{Wu}^{1}$, Nong $\mathrm{Gao}^{3}$, Marco J. Starink ${ }^{3}$, \\ ${ }^{1}$ School of Materials Science and Engineering, Harbin Institute of Technology, Harbin \\ 150001, China \\ ${ }^{2}$ Institute of Materials Research, Helmholtz-Zentrum Geesthacht, D-21502 Geesthacht, \\ Germany \\ ${ }^{3}$ Materials Research Group, Engineering Sciences, University of Southampton, \\ Southampton SO171BJ, UK
}

*Corresponding author. e-mail: xgqiao@ hit.edu.cn

\begin{abstract}
Coarse-grained $\mathrm{Mg}$ in the as-cast condition and fine-grained $\mathrm{Mg}$ in the extruded condition were processed by high pressure torsion (HPT) at room temperature for up to 16 turns. Microstructure observation and texture analysis indicate that to fulfil the Von Mises criterion, the non-basal slip is activated in the as-cast $\mathrm{Mg}$ and tension twinning is activated in the as-extruded $\mathrm{Mg}$. Although the deformation mechanism is different in the as-cast Mg and the as-extruded Mg during HPT, their hardening evolutions are similar, i.e. after 1/8 turn of HPT, microhardness of the as-cast Mg and the extruded Mg both show a significant increase and further HPT processing does not significantly further increase the microhardness. Texture strengthening can explain the rapid hardening. Hardness anisotropy and texture data results suggest that texture strengthening plays an important role for both types of samples. Texture strengthening weakens with decreasing grain size.
\end{abstract}

Key words: High pressure torsion; Magnesium; Non-basal slip; Tension twinning; Texture strengthening; Hardness anisotropy

\section{Introduction}


High pressure torsion (HPT) exhibits excellent ability of grain refinement in metals and alloys [1,2]. HPT differs from conventional torsion by imposing a large hydrostatic pressure of up to several GPa during processing. A large accumulated strain and grain refinement can be achieved through HPT since the hydrostatic pressure prevents crack initiation in the specimen during HPT process.

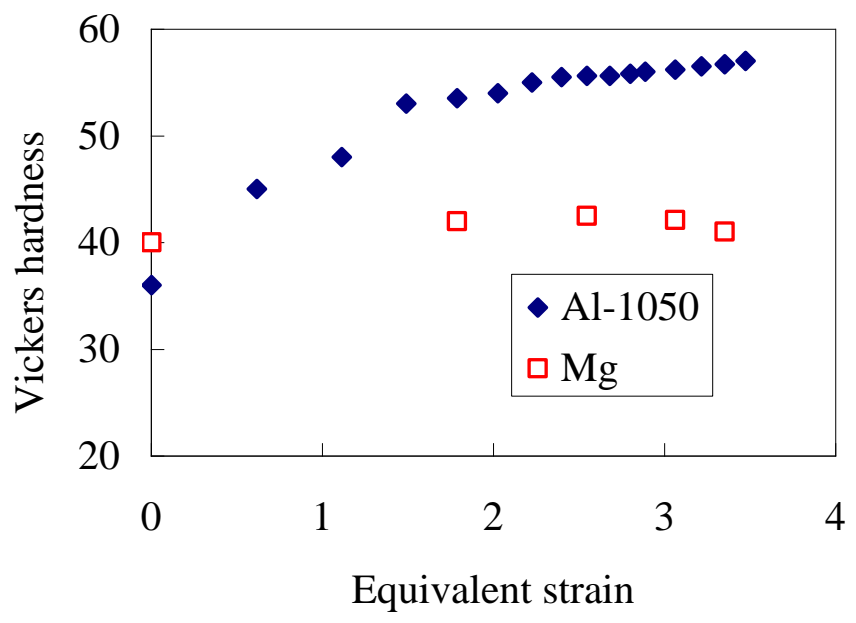

Fig. 1 Effect of the equivalent strain of HPT on Vickers hardness of Al1050 and the pure Mg processed by half a turn of HPT. Data of Al1050 and the pure Mg are from Refs 19 and 22, respectively.

HPT processing significantly increases yield strength and hardness of nearly all metals and alloys. Microhardness of HPT processed metals are improved up to $100 \%$ for pure $\mathrm{Al}[3,4], 130 \%$ for pure $\mathrm{Ti}[5,6], 400 \%$ for pure $\mathrm{Fe}$ [7] , $60 \%$ for pure $\mathrm{Cu}[8]$, and also for a range of other metals strong hardening has been evidenced $[9,10,11,12,13,14,15,16,17,18]$. This is because the HPT process imposes a very large shear strain on the metal and a very large amount of dislocations and/or twins are generated in the metals, which further cause significant microstructure refinement. For most metals, the increase in dislocation density and refinement of microstructure cause the microhardness of HPT processed metals to increase with the equivalent strain of the HPT processing, eventually reaching a saturated value for equivalent strains in the order of 3 to 8 (see e.g. [5,8]). For instance, as shown in Fig. 1, microhardness of Al-1050 processed by half a turn of HPT increases from $25 \mathrm{Hv}$ in as-cast condition to $36 \mathrm{Hv}$ at the 
disk centre, the hardness increases with the equivalent strain [19], and eventually becomes saturated. Further processing causes drop of hardness due to recovery (not shown in Fig. 1, see Ref [19]). Many metals and alloys including Al and Mg processed by HPT, or other SPD techniques, follow a similar trend [20, 21,22]. However, for $\mathrm{Mg}$, a relatively limited HPT deformation leads to steep increase of microhardness and further HPT processing does not remarkably increase its hardness further [22], see Fig. 1; microhardness of $\mathrm{Mg}$ processed by half a turn of HPT increases to $40 \mathrm{Hv}$ from $29 \mathrm{Hv}$ [22] at the disk centre where the equivalent strain is very limited, see Ref 22 for the completed dataset.

A recently developed model incorporating volume-averaged thermally activated annihilation of defects (typically dislocations) in the grains and grain boundary formation [23], indicates that the hardening and grain refinement of $\mathrm{Mg}, \mathrm{Al}$ and 15 other pure metals can be predicted well and it also indicates that defect recovery is stronger in $\mathrm{Mg}$ as compared to $\mathrm{Al}, \mathrm{Cu}, \mathrm{Ag}$ and a range of metals with higher melting temperatures. The latter can be the cause for saturation of hardening at lower strain as compared to Al. However, such a model [23] and other available models [24,25,26,27,28] can as yet not incorporate effects related to mixed defect types or starting and final texture. As will be shown in this work, all these factors play a role in HPT processed Mg alloys.

The different dependency of microhardness of $\mathrm{Mg}$ on the equivalent strain during HPT may be caused by its hexagonally close packed (hcp) structure which provides only two independent slip systems (basal slip) which are easily activated at the room temperature [29, 30, 31]. To fulfil the Von Mises criterion [32, 33], twinning and/or non-basal slip may be activated, which directly lead to texture change, and further cause a steep hardness increase at the beginning of HPT deformation. To test this possible explanation, we examined microstructure, microhardness and texture evolution of $\mathrm{Mg}$ during HPT. The aim of the current study is to reveal the deformation mechanism of the $\mathrm{Mg}$ and clarify the reason behind the different hardness evolution between $\mathrm{Mg}$ and other metals processed by HPT. Investigation of grain structures of HPT processed metals using Electron Backscatter Diffraction (EBSD) and scanning electron microscopy (SEM) has been extensively reported in the literature. Here we will use optical microscopy, 
transmission electron microscopy (TEM) and neutron diffraction which, as we will show, provide the essential information for analysis of hardening of the present pure $\mathrm{Mg}$ samples

\section{Experimental}

This work was carried out on commercially pure magnesium with purity of $99.8 \%$. The pure $\mathrm{Mg}$ was received in the as-cast state and was subsequently extruded to a rectangular bar at a temperature of $350{ }^{\circ} \mathrm{C}$ with extrusion ratio of $12: 1$. Disks of $9.8 \mathrm{~mm}$ in diameter were machined from the as-cast pure $\mathrm{Mg}$ and the extruded pure $\mathrm{Mg}$ with the circular surface parallel to the extrusion direction, see Fig. 2 (a). The disks were ground and polished to $0.85 \mathrm{~mm}$ thickness and subsequently processed by HPT for $1 / 8,1 / 4,1 / 2,1,2$, 4, 8 and 16 turns. All HPT processing was conducted at room temperature. During HPT a pressure of $6 \mathrm{GPa}$ was imposed on the disks and the anvil was rotated at $1 \mathrm{rpm}$. The processed disks were subsequently cold mounted, ground and polished.

The microstructures of the pure Mg in pre- and post-HPT conditions were observed by an Olympus D11 optical microscope (OM) and an FEI TECNAI G2 F30 transmission electron microscope. Preparation of the OM samples followed a well established procedure: they were mounted, ground, polished and etched by a water solution of 4 vol\% oxalic acid. OM images were taken on the large plane of the HPT samples, see Fig. 2 (a). The TEM samples were punched from the HPT sample at a position $2.5 \mathrm{~mm}$ to centre, followed by grinding, polishing and ion milling. The hardness of samples was tested using a Vickers microhardness tester set at constant load of $50 \mathrm{~g}$ held for $15 \mathrm{sec}$. Hardness was measured on the HPT sample from the centre to the edge. Distance between two indentations is $0.5 \mathrm{~mm}$ and one indentation is at each position.

Texture of the as-cast $\mathrm{Mg}$ and the extruded $\mathrm{Mg}$ processed by various turns of HPT was measured by the neutron diffractometer STRESS-SPEC located at the Heinz MaierLeibnitz Centre (Garching, Germany). The samples for the texture measurement were two stacked slices with width of $2 \mathrm{~mm}$ from the centre of two identical processed disks. 
The wavelength was $0.168 \mathrm{~nm}$ from a Ge (311) monochromator. The investigated gauge volume was $2 \times 2 \times 1.6-1.7 \mathrm{~mm}^{3}$ controlled by a primary slit and a radial collimator in front of the 2D- area detector. 1.6-1.7 $\mathrm{mm}$ is the thickness of the two stacked disks. Thickness of HPT processed $\mathrm{Mg}$ is from $0.85 \mathrm{~mm}$ to $0.80 \mathrm{~mm}$ depending on the turn number. Pole figures at three positions of the slice, e.g. centre, middle and edge, were measured using the automatic robot system at STRESS-SPEC [34], as shown in Fig. 2 (b) together with the definition of the sample coordinate system.
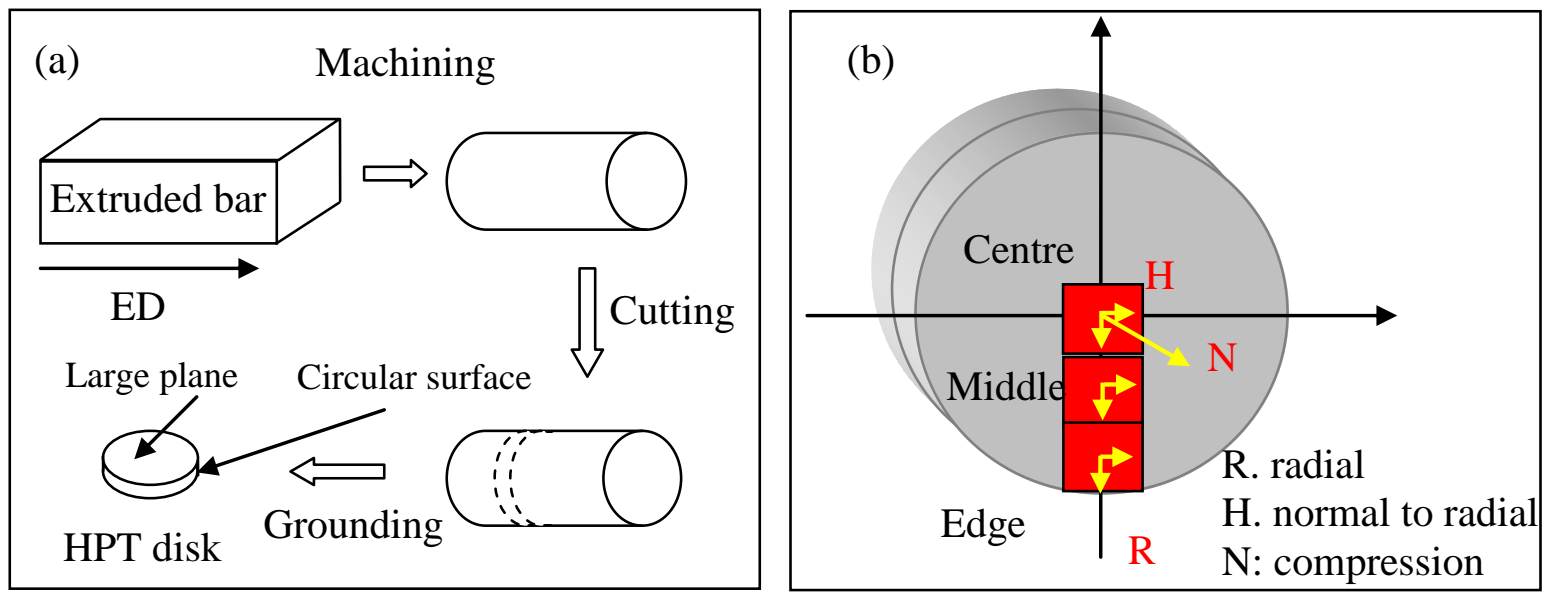

Fig. 2 Schematic illustration of (a) procedure of HPT sample preparation and (b) texture measurement positions on the HPT processed disk and corresponding directions. $\mathrm{N}$ direction is corresponding to the ED (extrusion direction of the extruding process). Two identical slices are stacked for texture measurement.

\section{Results}

\subsection{Microhardness of HPT processed Mg}

Fig. 3 (a) shows microhardness of the as-cast $\mathrm{Mg}$ and the $\mathrm{Mg}$ processed by various numbers of HPT turns, with the microhardness values measured on the large plane of the disk-shaped sample, see Fig. 2 (a). The X-axis values represent distances to the disk centre. The straight solid line in Fig. 3 (a) represents the microhardness of the as-cast $\mathrm{Mg}$, which is around $32 \mathrm{Hv}$. Fig. 3 (a) shows that the microhardness of the as-cast $\mathrm{Mg}$ increases to $42-45 \mathrm{Hv}$ after $1 / 8$ turn to 16 turns of HPT. It is noted that $1 / 8$ turn of HPT 
increases microhardness of the as-cast $\mathrm{Mg}$ to about $42 \mathrm{Hv}$ and increasing turns of HPT do not further increase its hardness, which is very different from most HPT processed FCC metals and alloys for which the microhardness generally increases with the equivalent strain until strain of 3 (see e.g. [5,8,19]). Furthermore, microhardness across the diskshaped sample is not homogeneous and it does not show any dependency on the distance from the disk edge to the centre although different positions on the disk experience different deformation (shear strain is proportional to the distance [19]).

Fig. 3 (b) shows microhardness of the as-extruded $\mathrm{Mg}$ and the as-extruded $\mathrm{Mg}$ processed by various turns of HPT. Definitions of axes, line and curves are exactly same as the Fig. 3 (a). The microhardness is again measured on the large plane of the disk-shaped sample. Microhardness of the as-extruded $\mathrm{Mg}$ is around $38 \mathrm{Hv}$. The result in Fig. 3 (b) are very similar to the hardening behaviour of the as-cast Mg during HPT in that 1/8 turn of HPT raises the microhardness of the as-extruded $\mathrm{Mg}$ substantially (to about $50 \mathrm{Hv}$ ), the microhardness also shows some limited inhomogeneity on the disk and is almost independent of HPT turns number or the equivalent strain.
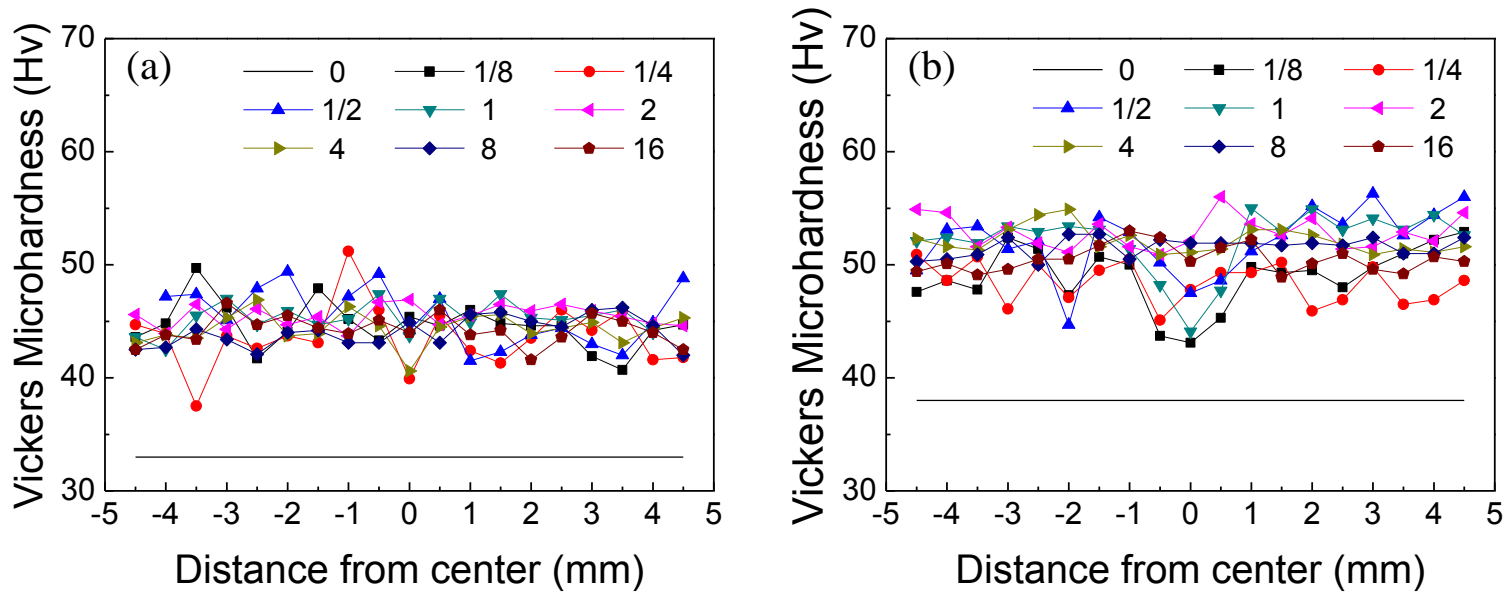

Fig. 3 Dependency of Vickers hardness on the distance to centre of $\mathrm{Mg}$ disks processed by various turns of HPT. (in the figure, $t$ stands for turn) (a) Pre-HPT disks are in as-cast condition; (b) Pre-HPT disks are in as-extruded condition 


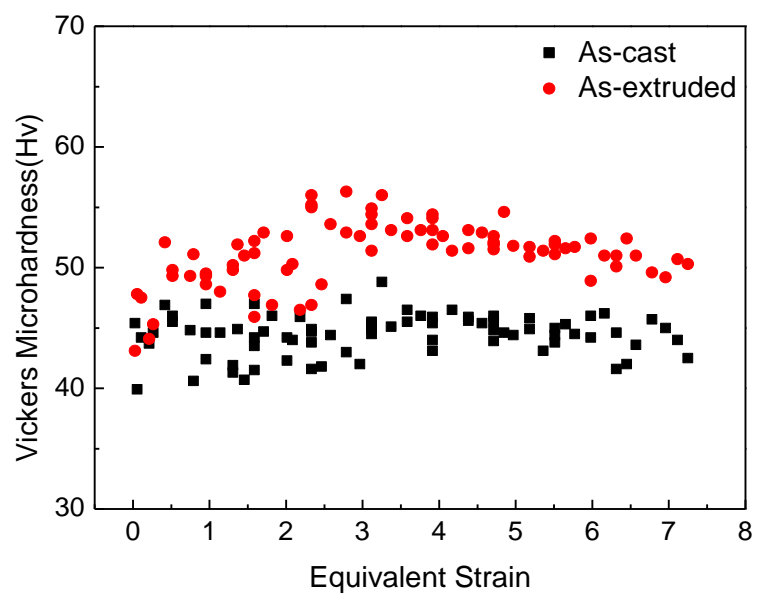

Fig. 4 Effect of the equivalent strain on microhardness of the as-cast $\mathrm{Mg}$ and the extruded $\mathrm{Mg}$ processed by various turns of HPT. The black squares represent disks processed by HPT from the as-cast condition; the red circles represent disks processed by HPT from the as-extruded condition.

Fig. 4 shows microhardness of the as-cast Mg and the extruded Mg after the various HPT turns plotted against the equivalent strain at the position where the microhardness was measured. The equivalent strain, $\varepsilon$, at each position is here calculated through $[19,35]$.

$$
\begin{gathered}
\gamma=\frac{2 \pi N}{h} \\
\varepsilon=\left(\frac{2}{\sqrt{3}}\right) \ln \left[\left(1+\frac{\gamma^{2}}{4}\right)^{\frac{1}{2}}+\frac{\gamma}{2}\right] \varepsilon=\frac{2}{\sqrt{3}} \ln \left[\left(1+\frac{\gamma^{2}}{4}\right)^{1 / 2}+\frac{\gamma}{2}\right]
\end{gathered}
$$

where $\gamma$ is the shear strain, $N$ is the number of rotations, $r$ is the distance from the centre of the sample, $h$ is its thickness. For discussion and analysis of the validity of the latter equations, see e.g. $[35,36,37,38,39,40,41,42,43]$. It is noted that the data at the equivalent strain very close to zero in Fig. 4 are obtained at the disk centre of the HPT processed as-cast $\mathrm{Mg}$ and extruded $\mathrm{Mg}$ and value of $r$ is taken as half a diagonal of the Vickers indentation. For the as-cast Mg (black squares in Fig. 4), at equivalent strain very close to zero, a remarkable hardness increase and scatter is observed. This hardness does increase further on raising the equivalent strain, however, the hardness values tend to be 
less scattered. The trends in data for extruded $\mathrm{Mg}$ are very similar to the as-cast $\mathrm{Mg}$ in terms of hardness evolution (red circles in Fig. 4), but the microhardness is higher. At equivalent strains from 1 to 3 , a slight increase of hardness can be seen for the extruded Mg.

\subsection{Microstructure of HPT processed Mg}

Fig. 5 shows optical microstructure of the as-cast Mg (Fig. 5 (a)) and the extruded Mg (Fig. 5 (b)). The microstructure of the as-cast $\mathrm{Mg}$ is very coarse: only two triple junctions are in the viewing field and grain size is larger than $1 \mathrm{~mm}$ (Fig. 5 (a)). The microstructure of the extruded Mg is significantly refined. The line intercept grain size is about $50 \mu \mathrm{m}$.
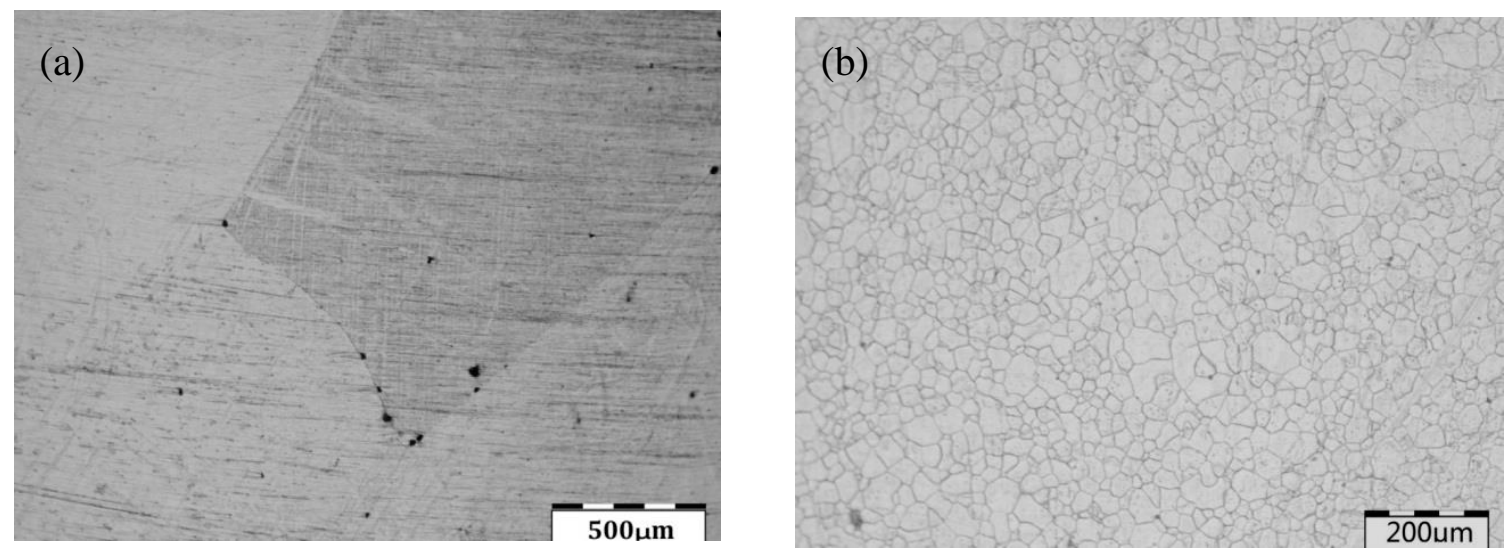

Fig. 5 Optical microscope images of $\mathrm{Mg}$ in (a) the as-cast condition and (b) the extruded condition.

Fig. 6 (a)-(d) shows optical microstructure of the as-cast Mg processed by 1/8, 1/4, 1/2 and one turn of HPT, respectively. Images were taken at about $2.5 \mathrm{~mm}$ from the disk centre. The viewing field in Fig. 6 is within an original grain since microstructure of the as-cast $\mathrm{Mg}$ is very coarse and no new grains are observed to form in the original grain of as-cast Mg processed by HPT up to 1 turn. However, one can still observe contrast in Fig. 6, which indicates that the original grain experiences deformation and the deformation is not homogeneous. No contrast is observed in the original grain before HPT, see Fig. 5 (a). The dark grey area in Fig. 6 experiences slightly heavier deformation and is easily etched whilst the light grey area is more homogenous and retains the original microstructure. 

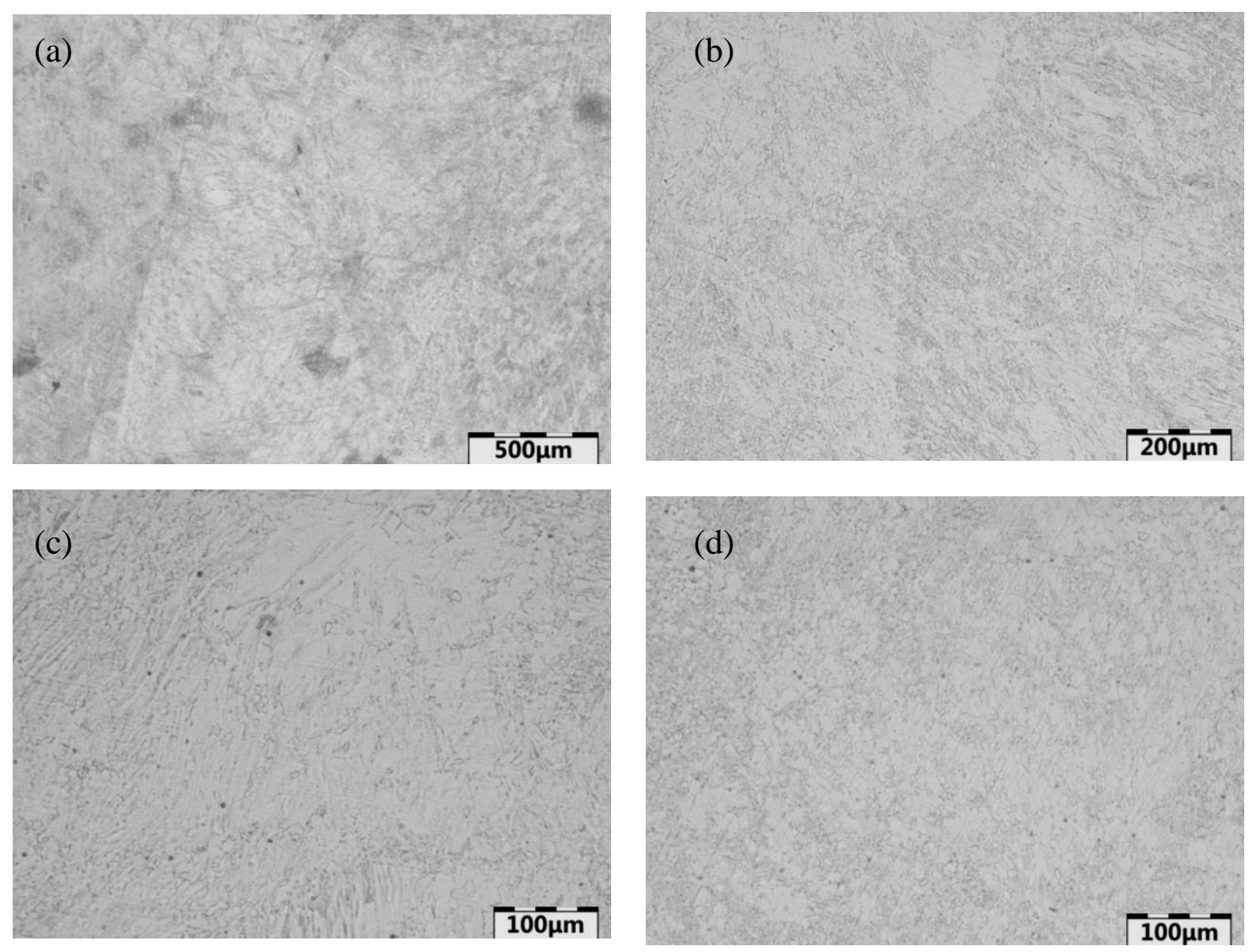

Fig. 6 Optical microscope images of the as-cast Mg processed by (a) 1/8; (b) 1/4: (c) 1/2; and (d) 1 turn of HPT

Fig. 7 (a)-(d) shows optical microstructure of the extruded $\mathrm{Mg}$ processed by 1/8, 1/4, 1/2 and one turn of HPT, respectively. Again, the images were taken about $2.5 \mathrm{~mm}$ from the disk centre. The original grain boundaries of the extruded $\mathrm{Mg}$ are well retained and the grain size does not change after HPT processing up to 1/2 turn (see Fig. 7 (a)-(c)). After one turn of HPT, some original boundaries start to become less distinct (see Fig. 7 (d)). Careful inspection of Fig. 7 reveals that different grains have different contrast and some grains contain a large amount of twins, which are not observed in the extruded $\mathrm{Mg}$ (see Fig. 5 (b)). 

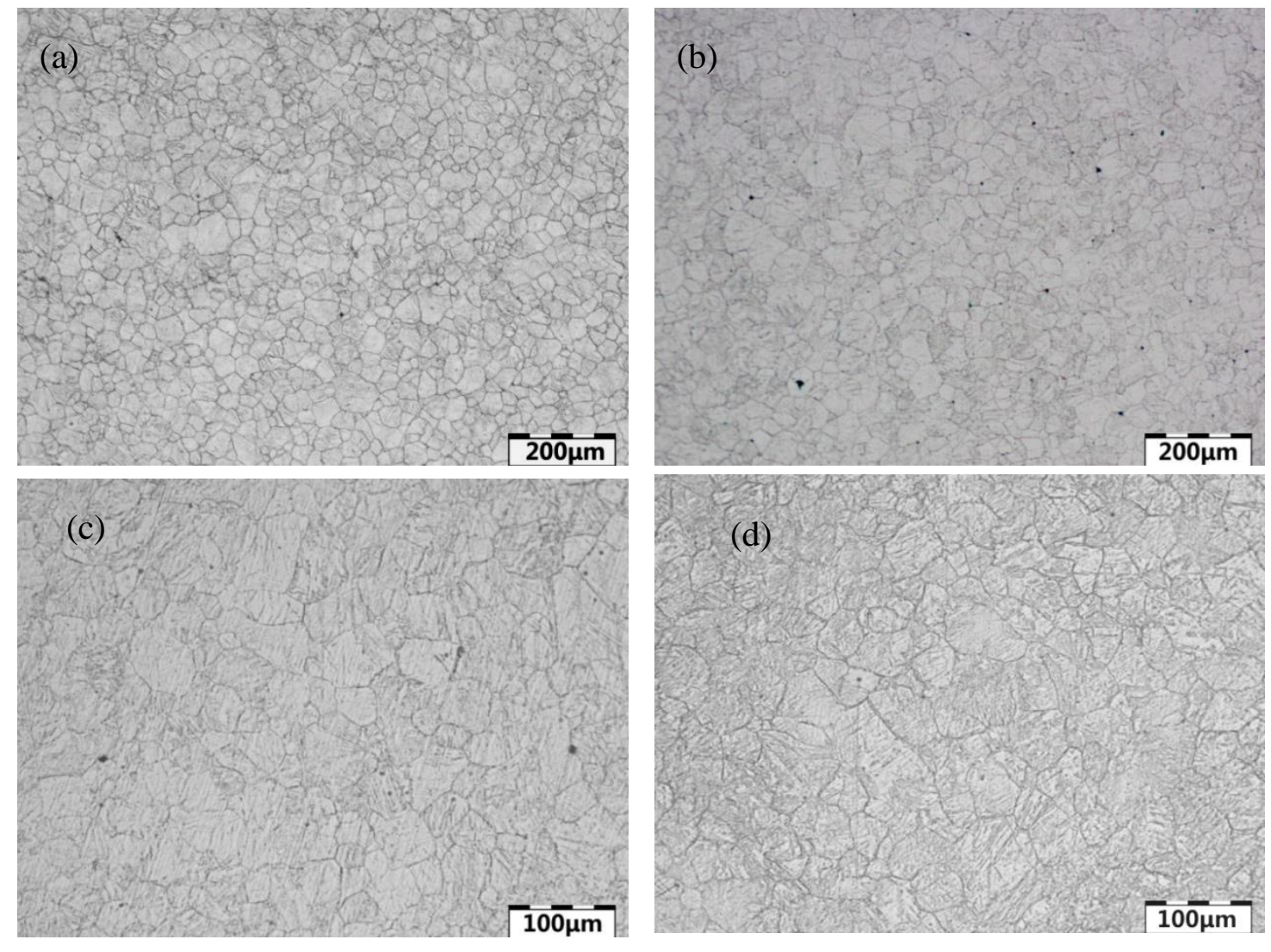

Fig. 7 Optical microscope images of the extruded Mg processed by (a) 1/8; (b) 1/4: (c) 1/2; and (d) 1 turn of HPT.

Fig. 8 (a) shows the microstructure of a disk-shaped sample of the extruded $\mathrm{Mg}$ processed by $1 / 8$ turn of HPT, which contains 30 images from the left edge to the right edge of the sample. It seems the centre area is less grey than the edges. Enlarged images of the centre area and the edge area are shown in Fig. 8 (b) and Fig. 8 (c), respectively. The original grains are well retained at the centre and twins can be observed, with the density of twins increasing with the distance to the centre, i.e. with increasing (equivalent) strain. Close to the centre very few twins can be observed and grain boundaries are very clear (Fig. 8 (b)). In the area close to the edge, twins and grain boundaries of original grains are not resolved. 


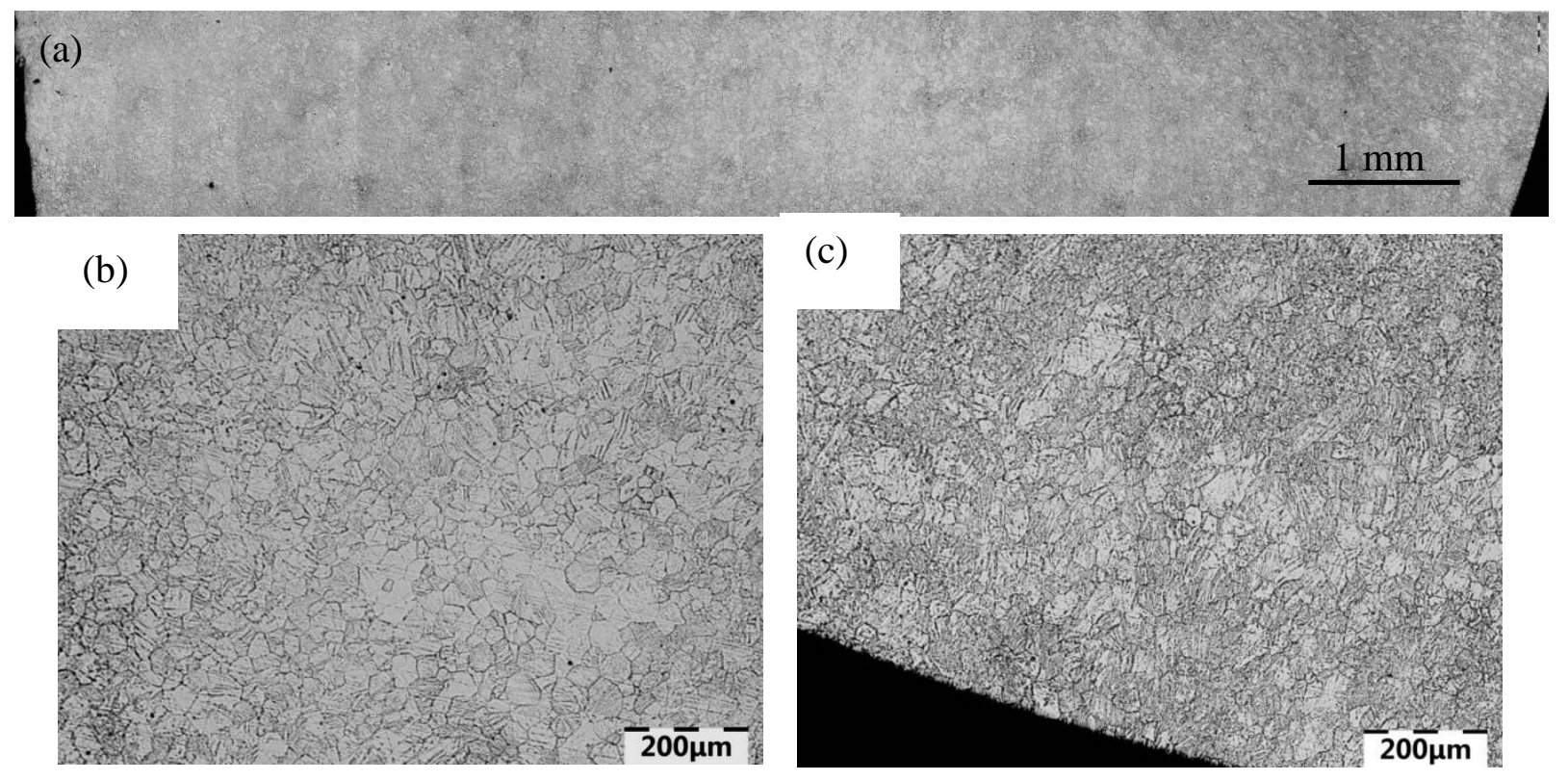

Fig. 8 Optical microscope images of the extruded Mg processed by 1/8 turn of HPT. (a) full image (b) enlarged image in the centre; (c) enlarged image in the area close to the edge.

The microstructure of the extruded Mg processed by HPT for more than one turn can not be clearly resolved with $\mathrm{OM}$, and is hence characterized by TEM. The TEM microstructure of the extruded Mg processed by one and eight turns of HPT at a position approximately $2.5 \mathrm{~mm}$ from the centre of the HPT sample is shown in Fig. 9 and Fig. 10, respectively. The microstructure of the extruded Mg processed by one turn of HPT is inhomogenous, with grain sizes ranging from $4 \mu \mathrm{m}$ (Fig. 9 (a)) to $0.5 \mu \mathrm{m}$ (Fig. 9 (b, c and d)). Many areas contain irregular fringes indicating highly anisotropic boundaries, which is typical for cold worked metals. The microstructure of the extruded $\mathrm{Mg}$ processed by eight turns of HPT is more homogenous, with grain sizes (mean linear intercept) around $0.6 \mu \mathrm{m}$ (Fig. $10(\mathrm{a}-\mathrm{d})$ ). Also in these samples many fringes are observed, see Fig. 10 (d). 

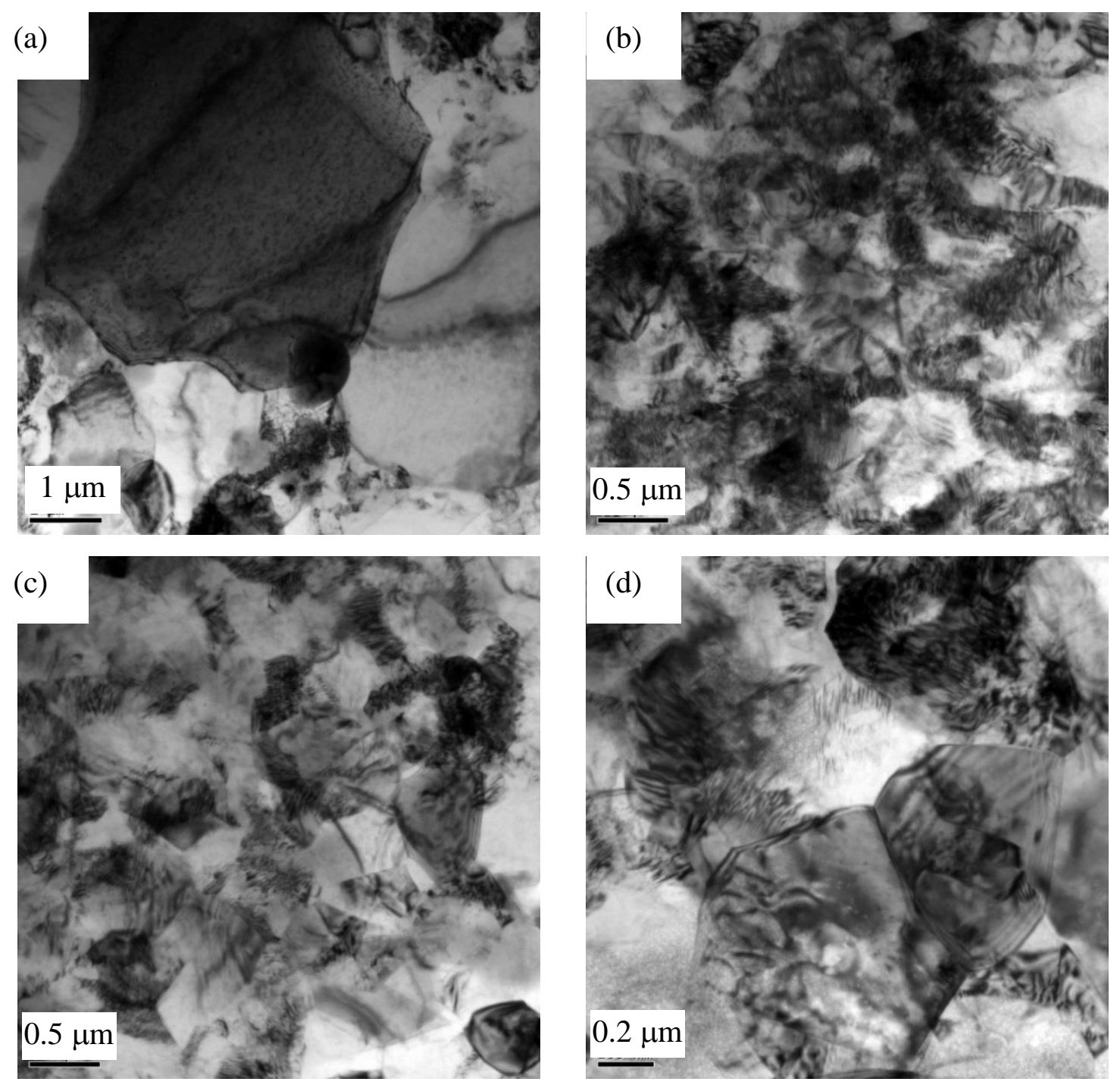

Fig. 9 TEM microstructure of the extruded Mg processed by one turn of HPT. (a)- (d) were taken in the middle of the disk about $2.5 \mathrm{~mm}$ to the centre.

\subsection{Texture evolution}

There is no preferred orientation in as-cast coarse-grained $\mathrm{Mg}$ (see [44]). Texture of the as-cast $\mathrm{Mg}$ processed by 1/8, one and eight turns of HPT is presented in Fig. 11 using (10.0) and (00.2) pole figures, respectively. Pole figures are obtained in the three positions in the each sample (see Fig. 2). After 1/8 turn of HPT, the maximum intensity (00.2) pole figure of all three positions show two kinds of distributions of the basal planes, i.e. some are parallel to the RH plane (shear plane) and the others are oriented about $45^{\circ}$ 
to the RH plane. After one turn of HPT, the basal planes of most grains are oriented parallel to the RH plane, which shows a typical torsion texture and is very similar to a $\mathrm{Mg}$ sample processed by free end torsion [45]. In addition, some grains with basal planes oriented about $45^{\circ}$ to the $\mathrm{RH}$ plane are present at the middle position. After eight turns of HPT, all three positions show a basal fibre with its axis about $15^{\circ}$ to the $\mathrm{RH}$ plane, even though the average shear strain experienced at the edge of the disk is three times that experienced at the midway position and 700 times at $0.5 \mathrm{~mm}$ from the centre.
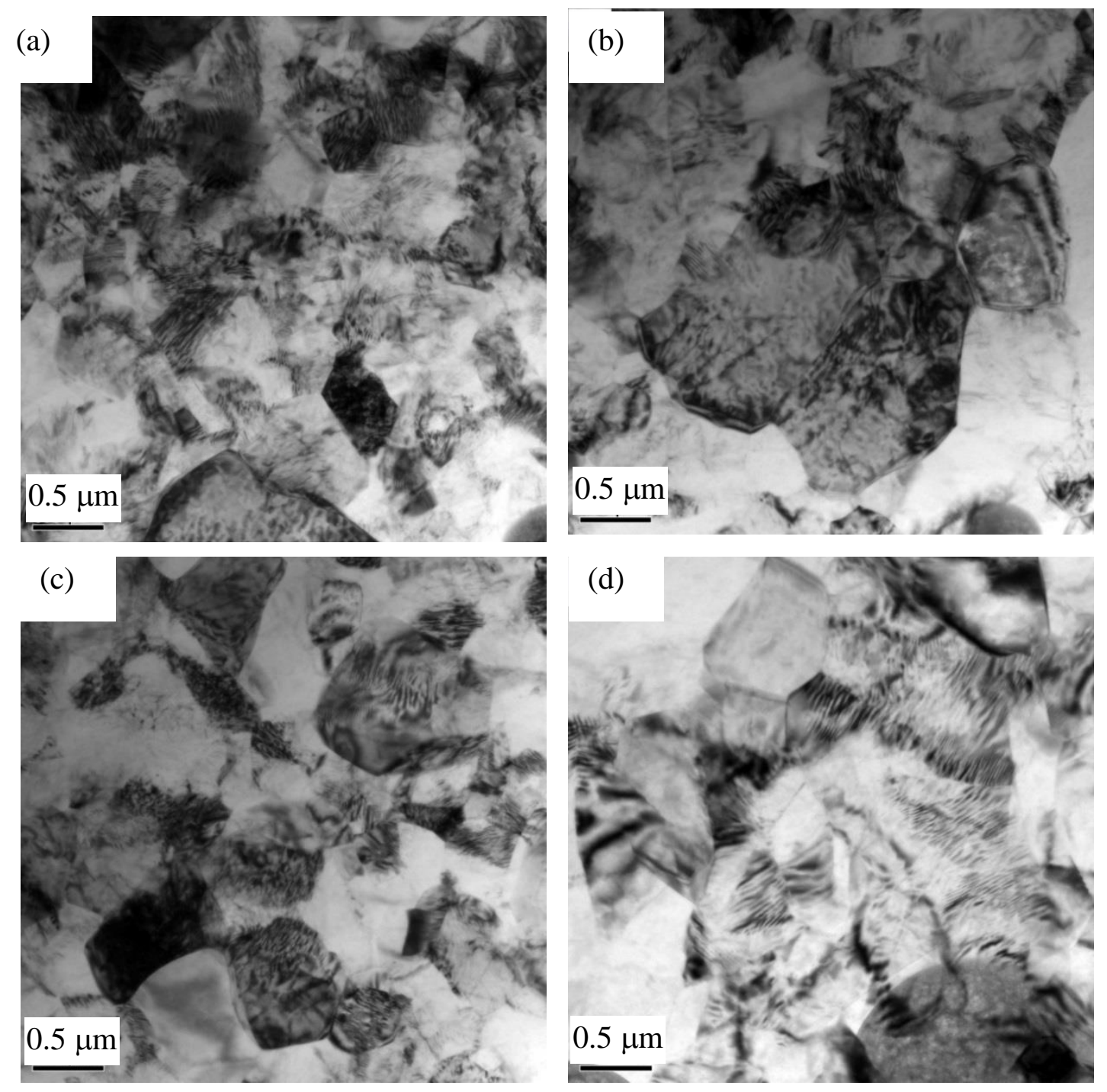

Fig. 10 TEM microstructure of the extruded Mg processed by eight turns of HPT. (a)- (d) were taken in the middle of the disk about $2.5 \mathrm{~mm}$ to the centre. 


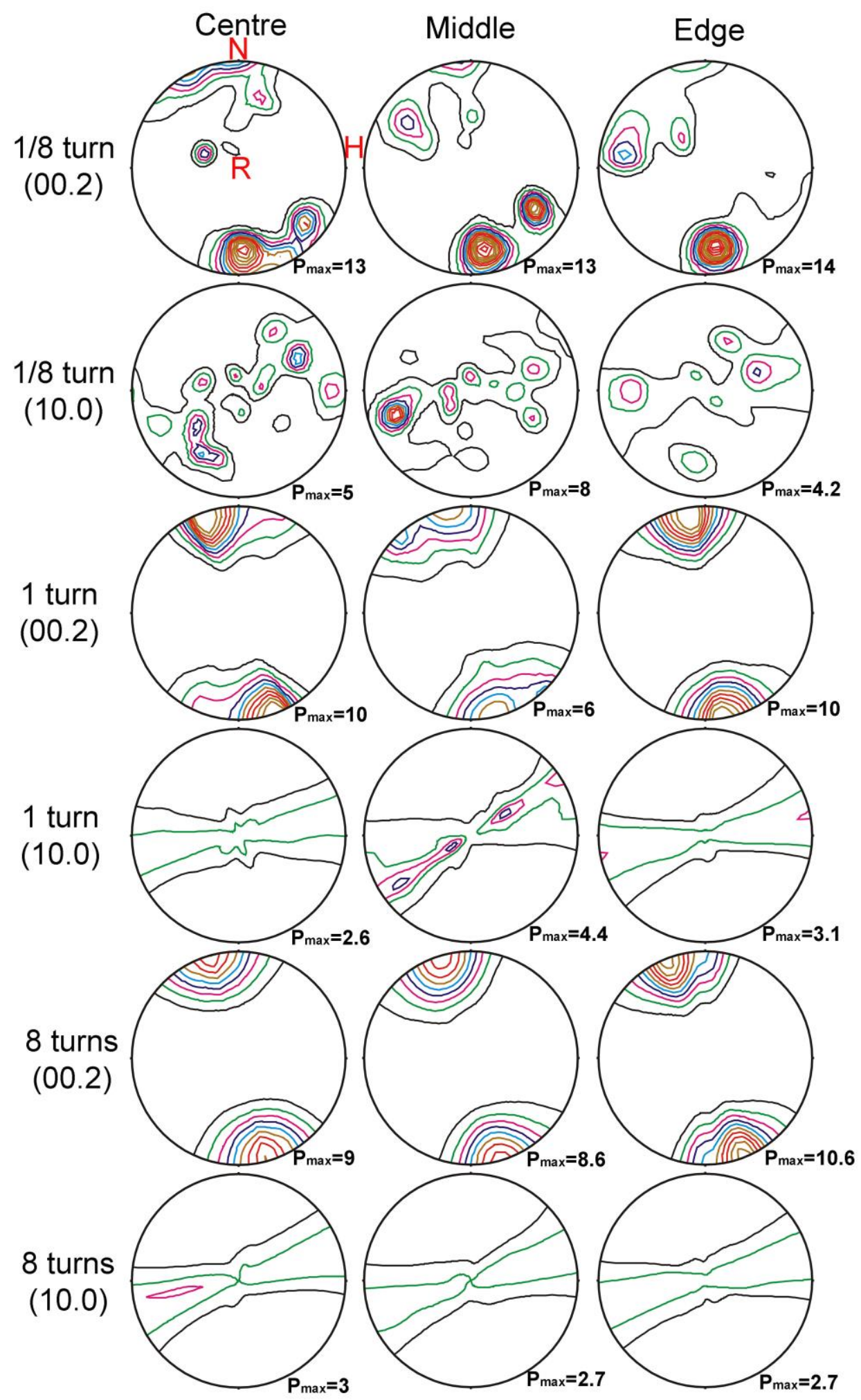

Fig. 11 Texture of the as-cast Mg processed by 1/8, one and eight turns of HPT. Definition of $\mathrm{R}, \mathrm{H}$ and $\mathrm{N}$ is presented in Fig. 2 (contour levels = 1.0x, 2.0x, 3.0x...). 
The extruded Mg possesses a typical extrusion texture (see Fig. 12) with the basal plane parallel to the extrusion direction. For the HPT of the extruded $\mathrm{Mg}$, the $\mathrm{N}$ direction (see Fig. 13) is parallel to the ED direction (see Fig. 12). Fig. 13 shows the (00.2) and (10.0) pole figures of the as-extruded pure Mg processed by HPT for $1 / 8$, one and eight turns, respectively. Definition of centre, middle and edge positions is the same as in Fig. 13 and Fig. 12. The (00.2) texture in Fig. 13 shows that after 1/8 turn of HPT the basal plane is about parallel to the shear direction, which is almost a $90^{\circ}$ rotation compared with the original extruded texture. The directions of the (10.0) planes, which are perpendicular to the basal plane, are more random, but we can still observe that from 1/8 turn to one turn of HPT the (10.0) planes tend to gather along the normal direction of the sample, which is perpendicular to the shear direction. After eight turns of HPT, the texture changes to the typical torsion texture of $\mathrm{Mg}$ [45]. Similar to the as-cast $\mathrm{Mg}$, the extruded $\mathrm{Mg}$ shows a stable texture after one turn of HPT. This is even though further processing involves very large shear strains.

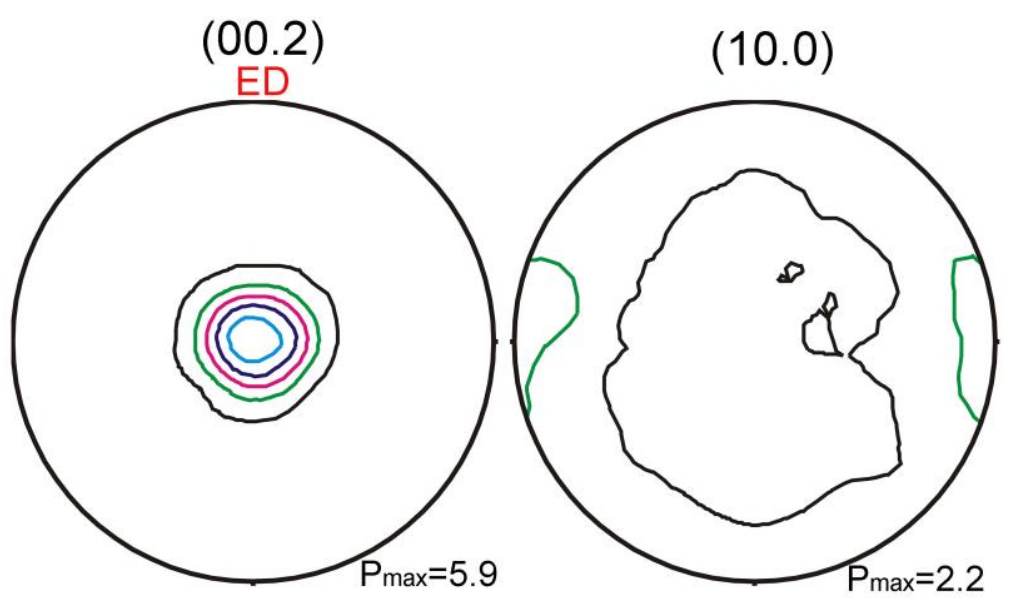

Fig. 12 Texture of the extruded Mg. Eextrusion direction is at the pole figure top, which is corresponding to the direction of $\mathrm{N}$, see Fig. 2 (contour levels $=1.0 \mathrm{x}, 2.0 \mathrm{x}, 3.0 \mathrm{x} \ldots$ ). 


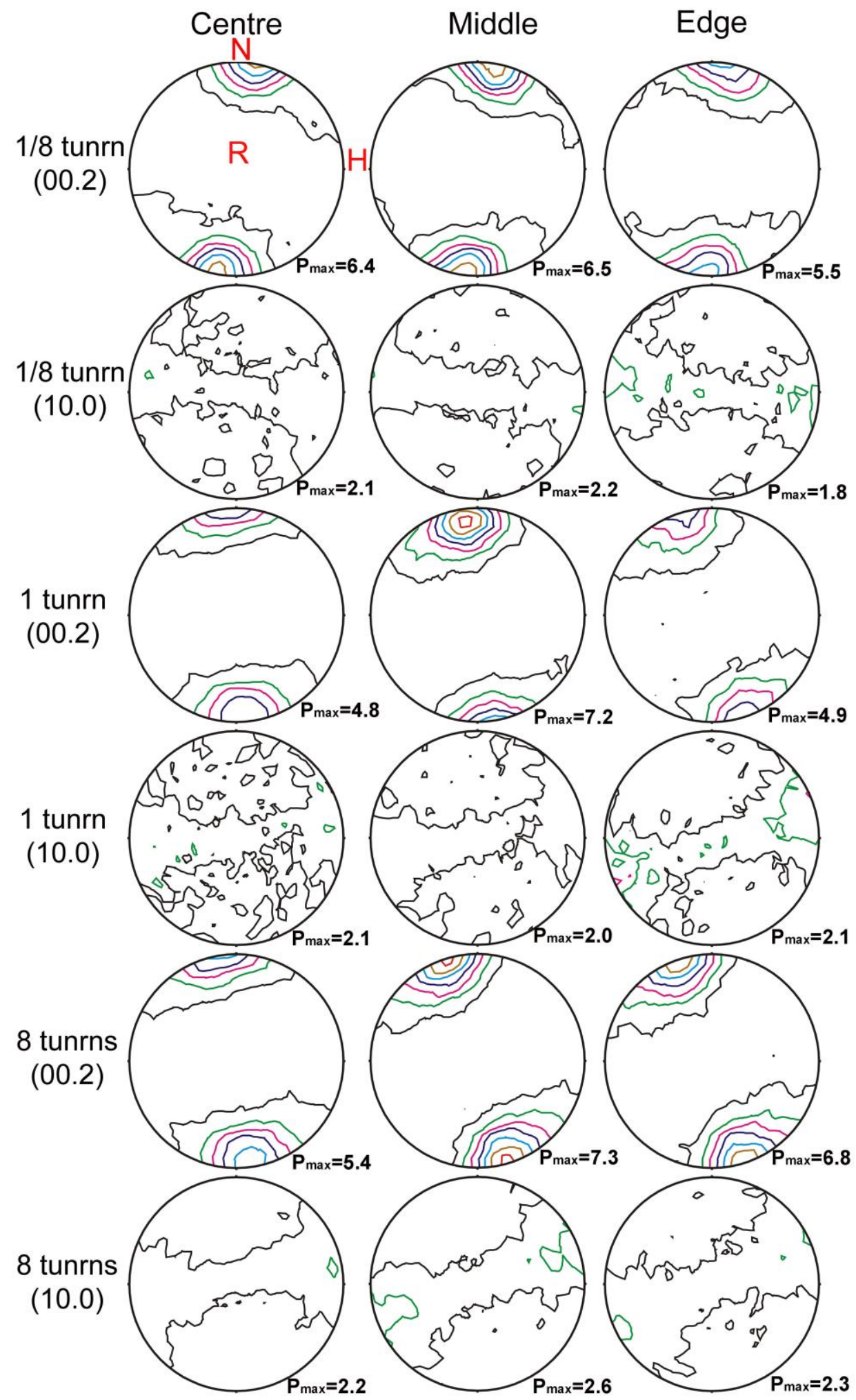

Fig. 13 Texture of the extruded Mg processed by 1/8, one and eight turns of HPT.

Definition of $\mathrm{R}, \mathrm{H}$ and $\mathrm{N}$ is presented in Fig. 2 (contour levels $=1.0 \mathrm{x}, 2.0 \mathrm{x}, 3.0 \mathrm{x} .$. ). 


\subsection{Hardness anisotropy}

For metals in which the number of slip systems is limited, such as $\mathrm{Mg}$, texture can cause a hardness anisotropy and can contribute to strength [46, 47]. The main factor determining this anisotropy is the basal slip which causes the slip systems to be limited to only two independent slip systems, which results in the (00.2) texture significantly influencing the strength and hardness of $\mathrm{Mg}$ in different orientations. Fig. 14 (a) shows the microhardness of the extruded Mg before HPT processing as measured on two planes: along and perpendicular to the extrusion direction. The microhardness of the extruded $\mathrm{Mg}$ with the loading direction along and perpendicular to the extrusion direction are 38 $\mathrm{Hv}$ and $50 \mathrm{Hv}$, respectively. Fig. 14 (b) shows the microhardness of the extruded $\mathrm{Mg}$ processed by eight turns of HPT. Microhardness measured on the large plane of the diskshaped sample (loading direction perpendicular to the basal plane) is much larger than the microhardness of the sample measured on the cross section (loading direction parallel to the basal plane). The difference of microhardness measured in different directions on the same sample as shown in Fig. 14 (a) and (b) is due to compression loading of the hardness test parallel to the basal plane causing tensile stress along the c axis, which readily activates the tension twinning, leading to a lower hardness value, whilst hardness testing with load perpendicular to the basal plane restricts the basal slip and causes activation of the non-basal slip, leading to a higher hardness value. This will be discussed in detail in section 4.3.
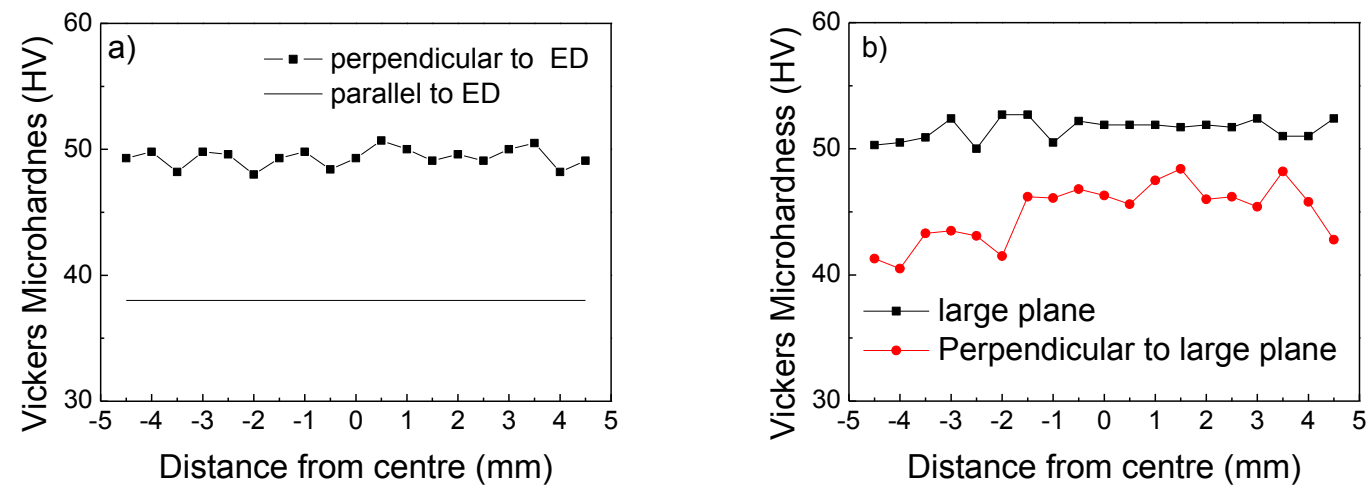

Fig. 14 Effect of the direction of the basal plane on the microhardness. (a) the extruded $\mathrm{Mg}$, (b) the extruded Mg processed by eight turns of HPT 


\section{Discussion}

\subsection{Model predictions of average hardness}

In the current study, the as-cast Mg and the extruded Mg are processed by HPT at room temperature for various turns. Both $\mathrm{Mg}$ samples show a significant increase in hardness due to HPT, and the hardness achieved in HPT processed as-cast Mg (45 HV) represents an increase, $\Delta \mathrm{HV}$, of $16 \mathrm{HV}$ as compared to the hardness of pure annealed $\mathrm{Mg}(29 \mathrm{HV}$, for description of the model and associated parameters see [23]) ${ }^{1}$. This measured $\Delta \mathrm{HV}$ of $16 \mathrm{HV}$ is in good agreement with the predicted value of $17 \mathrm{HV}$ based on a model incorporating volume-averaged thermally activated annihilation of defect in the grains and grain boundary formation [23]. The averaged hardness on the two planes for extruded $\mathrm{Mg}$ processed by eight turns of HPT (47 HV) is also in good agreement with the model predictions, with the small difference between the two types of HPT processed samples possibly being due to a slightly finer grain size in the extruded Mg processed by HPT resulting from the finer pre HPT grain size.

Thus the model based on volume-averaged thermally activated annihilation of defect in the grains and grain boundary formation can explain the hardening achieved in the present samples excellently [23]. To explain the details of defect formation in the present hcp metal, texture and hardness anisotropy, other factors need to be considered and this is discussed below.

\subsection{Deformation mechanisms of Mg during HPT}

To fulfil the Von Mises criterion [32,33], five independent slip systems are needed for an arbitrary plastic deformation in a polycrystalline aggregate. However, there are in total

\footnotetext{
${ }^{1}$ The model in Ref. [23] predicts the difference in hardness between maximum/saturated hardness of pure metals after HPT and a fully annealed pure metal (i.e. a pure metal very low density of defects such that no hardening due to defects occurs). The initial hardness of the present material (which is in as cast condition) is not part of the model and is hence not used in the assessment present in this paragraph. The model is formulated on the basis of volume averaged processes involving defects and does not take account of nor predict crystallographic texture, and hence hardness predictions are for hardness averaged over all indentation directions.
} 
four independent slip systems in the basal, prismatic and pyramidal a slip systems. The fifth independent slip system could be the $\langle\mathbf{c}+\mathbf{a}\rangle$ slip, although the critically resolved shear stress (CRSS) of the $<\mathbf{c}+\mathbf{a}>$ slip is very large. Alternatively, twinning can also be activated as "the fifth independent slip system". The most often observed twin in $\mathrm{Mg}$ is $\{10.2\}$ twin that is called tension twin [31] because it causes extension along c-axis when activated as $\mathrm{Mg}$ experiences tension stress along the c-axis.

During plastic deformation of $\mathrm{Mg}$, the slip system or twin to be activated depends on the CRSS for slip, activation stress for twin and the Schmid factor. In the present study, there are no twins observed in the as-cast Mg processed by HPT (see Fig. 6). This is because the as-cast $\mathrm{Mg}$ does not contain preferential textures and direction of the basal plane distributes randomly [44], so the Schmid factor does not favour the tension twining and twinning is suppressed. As a result the non-basal $\langle\mathbf{c}+\mathbf{a}\rangle$ slip is activated as the fifth slip system, which is consistent with the texture of the extruded $\mathrm{Mg}$ processed by various turns of HPT, see Fig. 11. The (00.2) pole figures of the extruded Mg processed by $1 / 8$ turn of HPT exhibits double textures, which indicates the non-basal $\langle\mathbf{c}+\mathbf{a}\rangle$ slip is activated along with the basal slip [48, 49 ].

For the extruded Mg processed by HPT up to one turn, a very large density of twins are observed (see Fig. 7). This is because the basal plane is parallel to the extrusion direction and perpendicular to the shear direction of HPT (see Fig. 12), and hence the Schmid factor of the basal plane is zero and the Schmid factor of the $\{10.2\}$ twining is about 0.5 , very close to the maximum value. As a result, the tension twinning is activated at the very start of the HPT processing and the basal slip is not. The $\{10.2\}$ tension twinning causes $86.3^{\circ}$ rotation of the basal plane [50], which is consistent with the texture measurement; see Fig. 12 and Fig. 13. The $\{00.2\}$ planes of the extruded Mg, which are perpendicular to the shear direction as shown in Fig. 12, rotate almost $90^{\circ}$ to the direction parallel to the shear direction after 1/8 turn of HPT (Fig. 13). During further HPT process, dislocation slip takes over the twinning as the dominant mechanism because of the basal plane rotation caused by the $\{10.2\}$ twinning. This is also consistent with the microstructure observation, e.g. in Fig. 7, the dark grey area increases with increasing HPT turns. 
The torsion deformation during HPT is driven by the static friction between the anvils and the $\mathrm{Mg}$ disk, which is achieved due to the very large pressure imposed on the disk. As a result, the Mg may be slightly compressed, for instance, the original sample and the sample after $1 / 8$ turn of HPT are $0.85 \mathrm{~mm}$ and $0.83 \mathrm{~mm}$ thick, respectively. It is reported that compression vertical to the $\mathbf{c}$ axis may activate $\{10.2\}$ tension twinning in AZ31 [51]. However, Fig. 8(b) shows that there are no twins near the centre of the extruded $\mathrm{Mg}$ after 1/8 turn of HPT (see Fig. 8(b)) and twin density increases with the distance to the centre, whilst the compression strain at the sample centre and the edge is identical. Thus, in the present experiments, the twinning is not caused by compression but torsion.

\subsection{Anisotropic hardness and strength of $\mathrm{Mg}$}

The strengthening mechanisms of metals are generally dislocation strengthening, precipitation strengthening, solid solution strengthening and grain boundary strengthening. The former three mechanisms take effect by obstructing dislocation motion in grains and the latter one impedes expansion of plastic deformation in the entire metal. For the pure $\mathrm{Mg}$, only grain refinement and dislocation density need to be considered. However, as is illustrated by Fig. 14, also hardness anisotropy plays a role, and this is related to the texture.

Microhardness of the as-cast $\mathrm{Mg}$ significantly increases within 1/8 turn of HPT processing. This cannot be explained by just dislocation hardening and grain size hardening, because the observed grain refinement is too limited to explain the level of hardening (see e.g. [23]) and dislocation density at this limited equivalent strain should be relatively low, especially for the centre area. It is thought that texture strengthening is an important factor in this early hardening during HPT, and particularly the basal texture changes should have an influence. The basal planes change from a randomly arrangement in the as-cast condition to an arrangement parallel to the shear direction, i.e. vertical to the loading direction of the microhardness tests (see Fig. 11). So the hardness of the ascast $\mathrm{Mg}$ can increase after just 1/8 turn of HPT due to texture strengthening. 
The extruded Mg also shows remarkable increase of microhardness (see Fig. 3) after only $1 / 8$ turn of HPT because the basal plane rotated about $90^{\circ}$ to parallel to the shear direction. Also for this sample, the hardness values show some scatter (see Fig. 4) at low equivalent strain due to the inhomogeneous microstructure and the non-uniform texture. As shown in Fig. 7 and Fig. 8, not every grain contains twins and some areas are light grey and others are dark. The scattered hardness converges at higher equivalent strain because the microstructure and texture tends to become more uniform (see Fig. 9, Fig. 10 and Fig. 13).

The hardening of the extruded Mg and the as-cast Mg processed by HPT differ from each other in both the maximum hardness reached as well as early saturation for the as-cast Mg processed by HPT (see Fig. 4). The strengthening model outlined in [23] (with grain size strengthening based on Hall-Petch type strengthening) predicts that the hardness of as-cast $\mathrm{Mg}$ (i.e. $\mathrm{Mg}$ with a very large starting grain size) processed by HPT saturates at $44 \mathrm{HV}$ (here the final grain size is predicted using the model in [23] which is consistent with data in [52]). The same model predicts that the hardness of a Mg sample processed by HPT with grain size further refined to $0.6 \mu \mathrm{m}$ (as seen in the TEM pictures for the asextruded sample processed by HPT Fig. 10) saturates at $51 \mathrm{HV}$. Both predictions are in excellent agreement with the measured hardness data in Fig. 4. Thus the hardening due to HPT is ascribed to dislocation strengthening and grain boundary strengthening [23] and the difference in saturated hardness is ascribed primarily to the grain size of the extruded $\mathrm{Mg}$ being finer than the as-cast $\mathrm{Mg}$, which causes the grain size of former to be smaller than the latter after HPT processing.

Texture strengthening/softening play a very important role in hcp metals and has been extensively studied, especially for titanium [53]. In Mg alloys, for instance, the AZ31 alloy [46], the texture even takes the dominant position in strengthening contributions to the yield strength (see Ref [47,54] for more examples). Consequently, Mg samples with a strong texture can show significant hardness anisotropy, as was revealed for our samples in Fig. 14. To evaluate the influence of microstructure on hardness anisotropy and texture 
strengthening, we consider the following treatment. The yield strength, $\sigma_{\mathrm{y}}$, of a polycrystal is generally given by:

$$
\sigma_{y}=M \tau_{c}+k_{H P} d^{-1 / 2}
$$

where $\tau_{\mathrm{c}}$ is the critically resolved shear stress of the grain, $M$ is a factor related to the number of slip systems to be activated and their orientations, $k_{\mathrm{HP}}$ is a proportionality factor in the Hall-Petch type treatment of grain size dependency. In materials in which substantial slip systems are available, e.g. in fcc metals, $M$ is often termed the Taylor factor. In many alloys the hardness is proportional to the yield strength i.e. $\mathrm{HV}=\mathrm{C} \sigma_{\mathrm{y}}$. So in an isotropic material the following should hold:

$$
\frac{H V}{C}=M \tau_{c}+k_{H P} d^{-1 / 2}
$$

In our samples, orientation of slip systems and their activation is anisotropic, which means $M$ will be dependent on indentation direction, whilst for similar reasons also $k_{\mathrm{HP}}$ is likely to be orientation dependent. We would thus find:

$$
\begin{array}{lr}
\frac{H V_{o 1}-H V_{o 2}}{C}=\left(M_{o 1}-M_{o 2}\right) \tau_{c}+\left(k_{H P, o 1}-k_{H P, o 2}\right) d^{-1 / 2} & \text { Eq } 5 \\
\frac{\Delta H V_{a n}}{C}=\Delta M \tau_{c}+\Delta k_{H P} d^{-1 / 2} & \text { Eq } 6
\end{array}
$$

Fig. 15 shows the hardness anisotropy in our samples as a function of $d^{-1 / 2}$, with $\Delta \mathrm{HV}_{\text {an }}$ representing the difference of microhardness measured on the same sample along the directions parallel and perpendicular to the basal plane. The data is for the as-cast $\mathrm{Mg}$ processed by $1 / 8$ turn of HPT, the extruded $\mathrm{Mg}$ and the extruded Mg processed by eight turns of HPT (data taken from Fig. 3, Fig. 5, Fig. 10 and Fig. 14). The data in Fig. 15 is close to being on a straight line, which supports the above analysis. The abcissa with the vertical axis is at $\Delta \mathrm{HV}_{\mathrm{an}}=14 \mathrm{HV}$, which, according to the latter equation, should equal $\mathrm{C} \Delta M \tau_{\mathrm{c}}$. As $\mathrm{C} M \tau_{\mathrm{c}}$ should equal about $45 \mathrm{HV}$, we find $\Delta M / M=0.3$. This is not unreasonable seeing that $M$ values for textured fcc metals can vary in similar magnitude. Extrapolation in Fig. 15 further suggest that $\Delta \mathrm{HV}_{\text {an }}$ changes sign at about $d=0.2 \mu \mathrm{m}$. This can be rationalised as follows. 


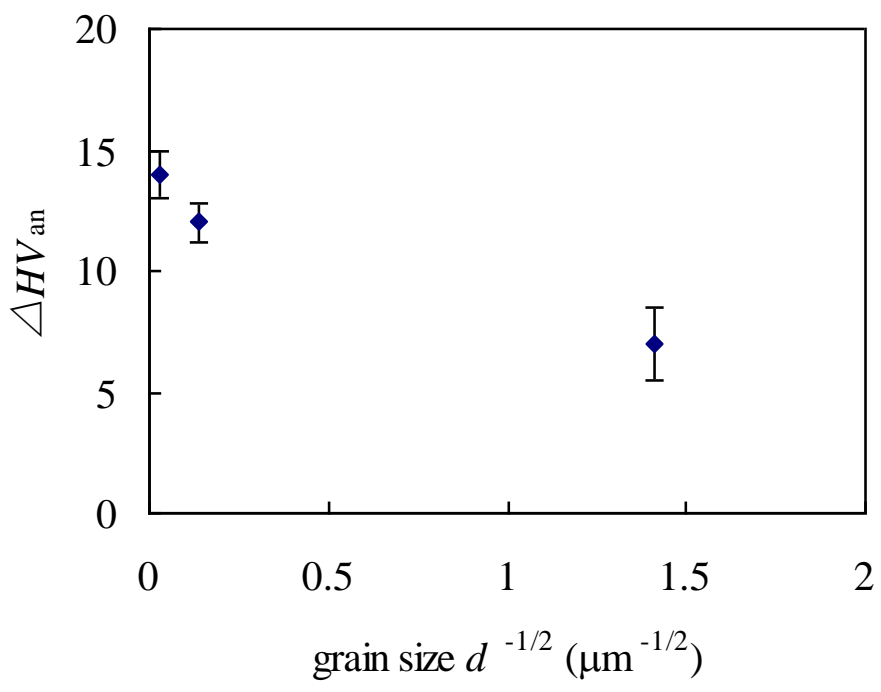

Fig. 15 Dependency of hardness anisotropy on $d^{-1 / 2}$.

Texture strengthening of $\mathrm{Mg}$ is generally caused by deformation along the forming direction (rolling, extruding or shearing) which limits the basal slip and is beneficial to the activation of the non-basal slips, thus increasing the yield strength. In single crystal $\mathrm{Mg}$ [55], the CRSS of non-basal slip is two orders higher than the basal slip at the room temperature and there are very limited number of reports [56,57] in which non-basal slips were observed after deformation at room temperature. On the other hand, polycrystalline $\mathrm{Mg}$ shows a fairly good ductility at room temperature (elongation up to 20\%) which indicates that non-basal slip is more easily activated than in a single crystal. The CRSS ratio between non-basal and basal slip decreases from 100 for a single crystal Mg to 1.1 [58] (grain size $6.5 \mu \mathrm{m}$ ) and 2.5 [59] (grain size $9 \mu \mathrm{m}$ ) for a polycrystalline AZ31 at room temperature. Whilst the solutes in AZ31 may play a role, the low CRSS ratio of the polycrystalline $\mathrm{Mg}$ alloy at room temperature indicates that the easier activation of nonbasal slips is due to grain boundaries $[58,59,60]$, and three effects can be considered. Firstly, large stress concentration caused by dislocation pile-ups at the grain boundaries benefits the non-basal slips. Secondly, compatibility stress, created near grain boundaries when dislocations move in different direction in the adjacent grains, forces the non-basal slips to activate. Third, grain boundaries may be potential sources of non-basal 
dislocations. Thus, activation of non-basal slips become easier with decreasing grain size and texture strengthening effect is weakened.

On the other hand, deformation perpendicular to the forming direction may also limit the basal slip but enable the tension twinning and correspondingly lead to a lower yield strength, which is sometimes called texture softening. Dependency of mechanical twinning and the grain size of Mg alloys is very different to fcc metals. For instance in $\mathrm{Al}$ alloys [61] mechanical twinning is more favoured than the dislocation slip because forming a perfect dislocation is less energetically economical than forming a partial dislocation to nuclear a twin when grain size is in nanometre scale [62]. Activation of twinning in $\mathrm{Mg}$ alloys becomes more difficult with decreasing grain size and slip may take over twinning as the dominant mechanism, for instance, at $150{ }^{\circ} \mathrm{C}$, a grain size below $4 \mu \mathrm{m}$ suppresses the tension twinning of AZ31 [63,64]. The reasons for this are not very clear, one possible explanation is that twinning nucleates at grain boundaries where dislocations used to form twins are stored and numbers of twins formed is proportional to grain boundary area $[63,65,66]$. In this case, smaller grain size leads to a larger grain boundary area per unit volume and a larger twin density but a smaller twin number per grain. Therefore, a larger stress is required to make a fine-grained $\mathrm{Mg}$ yield than a coarsegrained $\mathrm{Mg}$, as a result, non-basal slip may be activated in the fine-grained $\mathrm{Mg}$.

In summary, the hardness anisotropy is caused by competition of activation of the nonbasal $\langle\mathbf{a}+\mathbf{c}\rangle$ slips and tension twinning to achieve strain along $\mathbf{c}$ axis during compression along or vertical to c axis. Our data (Fig. 15) and the above discussion indicates that the hardness anisotropy decreases with decreasing grain size which is due to grain boundaries promoting the non-basal $\langle\mathbf{a}+\mathbf{c}\rangle$ slip which restricts the tension twinning and further causes a weakening of texture strengthening/softening effects. Extrapolation in Fig. 15 suggests that the hardness anisotropy disappears when grain size is about $0.2 \mu \mathrm{m}$ and below this grain size, the hardness anisotropy may be reverse. This critical grain size is thought to be related to the grain size at which the deformation mechanism changes from twinning to non-basal $\langle\mathbf{a}+\mathbf{c}>$ slips, i.e. below this critical grain size twinning will not be activated, and only non-basal $\langle\mathbf{a}+\mathbf{c}\rangle$ slips can be activated. The critical grain size of 0.2 
$\mu \mathrm{m}$ is broadly consistent with graphs in the work by Barnett and co-workers $[62,64]$ which shows the grain size at which deformation mechanism changes from slip to twinning in AZ31 is $8 \mu \mathrm{m}$ to $15 \mu \mathrm{m}$ at $200^{\circ} \mathrm{C}, 4 \mu \mathrm{m}-10 \mu \mathrm{m}$ at $150{ }^{\circ} \mathrm{C}$, extrapolating to $\sim 0.4 \mu \mathrm{m}[62]$ at room temperature.

\section{Conclusions}

The coarse grained commercially pure $\mathrm{Mg}$ in the as-cast condition and the fine grained pure $\mathrm{Mg}$ in the as-extruded condition are processed by HPT at room temperature for $1 / 8$, $1 / 4,1 / 2,1,2,4,8$ and 16 turns. Conclusions are drawn as follows:

(a) Microhardness of pure Mg processed by HPT reaches a near constant value after 1/8 turn of HPT, further HPT deformation does not increase the microhardness.

(b) The large density of twins observed in the extruded Mg processed by HPT at room temperature up to 1 turn is due to the torsion, i.e. the shear stress during HPT perpendicular to the basal plane activates a tension twin.

(c) Texture of the basal plane parallel to the shear stress of the HPT is developed within 1/8 turn of HPT. It is due to the activation of non-basal slip for the as-cast Mg sample and tension twinning for the extruded $\mathrm{Mg}$ sample.

(d) The maximum hardening due to HPT can be represented well by a model incorporating volume-averaged thermally activated annihilation of defects in the grains and grain boundary formation [23].

(e) Hardness anisotropy is present in the samples which have been thermo-mechanically processed, i.e. the extruded and the HPT processed samples. The hardness anisotropy decreases with decreasing grain size. The grain size dependency is consistent with basic hardening theory incorporating an orientation dependent $M$ factor (equivalent to the Taylor factor) and a $d^{-1 / 2}$ dependency in line with the Hall-Petch type grain size hardening.

\section{Acknowledgements}


Professor Heinz-Günter Brokmeier of Clausthal University of Technology is gratefully acknowledged on discussion of texture measurement. XGQ thanks funding from the Fundamental Research Funds for the Central Universities under Grant No. HIT. NSRIF.2015003, the National Natural Science Funds of China under Grant No 51301051, the General Financial Grant from the China Postdoctoral Science Foundation under Grant No 2013M531034, Specialized Research Fund for the Doctoral Program of Higher Education under Grant No 20132302120001, Hei Long Jiang Postdoctoral Foundation, the Scientific Research Foundation for the Returned Overseas Chinese Scholars, State Education Ministry and the Engineering and Physical Sciences Research Council (EPSRC) PhD plus Grant No. EP/P503841/1. 


\section{References:}

1. R.Z. Valiev, I.V. Alexandrov, Ann.Chim.Sci.Mat. 27 (2002) 3-14.

2. R.Z. Valiev, T.G. Langdon, Prog Mater Sci 51 (2006) 881-981.

3 Y. Harai, Y. Ito, Z. Horita, Scripta Mater. 58 (2008) 469-472

4 X.G. Qiao, N. Gao, M.J. Starink, Phil Mag 92 (2012) 446-470

5 K. Edalati, E. Matsubara, Z. Horita, Metall. Mater. Trans. A, 40 (2009) 2079-2086

6 Y. J. Chen, Y.J. Li, J.C. Walmsley, N. Gao, H.J. Roven, M.J. Starink, T.G. Langdon, J Mater Sci, 47 (2012) 4838-4844

7 K. Edalati, T. Fujioka, Z. Horita, Mater. Trans., 50 (2009) 44-50

8 K. Edalati, T. Fujioka, Z. Horita Mater. Sci. Eng. A, 497 (2008) 168-173

9 K. Edalati, Z. Horita, Y. Mine, Mater Sci Eng A 527 (2010) 2136-2141

10 K. Edalati, Y. Ito, K. Suehiro, Z. Horita, Int J Mater Research 100 (2009) 1668-1673

11 K. Y. Mulyukov, G.G. Korznikova, R.Z. Valiev, Phys Stat Sol a 125 (1991) 609-614

12 Y.R. Kolobov, B. Kieback, K.V. Ivanov, T. Weissgaerber, N.V. Girsova, Y.I. Pochivalov, G.P. Grabovetskaya, M.B. Ivanov, V.U. Kazyhanov, I.V. Alexandrov, Int. J. Refract. Met. Hard Mater 21 (2003) 69-73

13 R. Wadsack, R. Pippan, B. Schedler, Fusion Eng Design 66-68 (2003) 265-269

14 Q. Wei, H.T. Zhang, B.E. Schuster, K.T. Ramesh, R.Z. Valiev, L.J. Kecskes, R.J. Dowding, L. Magness, K. Cho, Acta Mater 54 (2006) 4079-4089

15 Z.Z. Jiang, S.H. Yu, Y.B. Chun, D.H. Shin, S.K. Hwang, Mater Sci Eng A, 479 (2008) 285-292

16 Q. Wei, Z.L. Pan, X.L. Wu, B.E. Schuster, L.J. Kecskes, R.Z. Valiev, Acta Mater, 59 ( 2011) 2423-2436

17 E.N. Popova, V.V. Popov, E.P. Romanov, V.P. Pilyugin, Phys Met Metall 101 (2006) $52-57$

18 V. V. Popov, E.N. Popova, A.V. Stolbovskiy, Mater Sci Eng A 539 (2012) 22-29

19 J. Zhang, M.J. Starink, N. Gao. Mater Sci Eng A 528 (2011) 2581-2591.

20 M. Kawasaki, J Mater Sci 49 (2014) 18-34

21 M. Kawasaki, H-J Lee, B. Ahn, A.P. Zhilyaev, T.G. Langdon, J Mater Res Techn, 2014, in press, http://dx.doi.org/10.1016/j.jmrt.2014.06.002.

22 K. Edalati, A. Yamamoto, Z. Horita, T. Ishihara, Scripta Mater. 64 (2011) 880-883

23 M.J. Starink, X. Cheng, S. Yang, Acta Mater., 61 (2013) 183-192

24 S.C. Baik, Y. Estrin, H.S. Kim, R.J. Hellmig, Mater Sci Eng A, 351 (2003) 86-97

25 Y. Estrin, L.S. Toth, A. Molinari, Y. Brechet, Acta Mater, 46 (1998) 5509-5522

26 X. Huang, N. Kamikawa, N. Hansen, Mater Sci Eng A, 483-484 (2008) 102-104

27 L.S. Toth, Y. Estrin, R. Lapovok, C. Gu, Acta Mater 58 (2010) 1782-1794

28 M.J. Starink, X.G. Qiao, J. Zhang, N. Gao, Acta Mater, 57 (2009) 5796-5811 
29 G.W. Groves, A. Kelly Phil Mag, 8 (1963) 877-887

30 P.B. Hirsch, J.S. Lally, Phil Mag 12 (1965) 595 - 648

31 M.H. Yoo, Metall. Trans. A 12 (1981) 409-418.

32 R. Von Mises, Z. Angew. Math. Mech. 8 (1928)161-185

33 G.I. Taylor, J. Inst. Met. 62 (1938) 307-338

34 H.G. Brokmeier, W.M. Gan, C. Randau, M.Voeller, J. Rebelo-Kornmeier, M.

Hofmann, Nucl Instrum Methods Phys Res Sect A 642 (2011) 87-92

35 N.H. Polakowski, E.J. Ripling, Strength and Structure of Engineering Materials,

Prentice-Hall, Englewood Cliffs, NJ,1966.

36 S.C. Shrivastava, J.J. Jonas, G. Canova, J Mech Phys Solids 30 (1982) 75-90

37 H.P. Stuwe, Adv. Eng. Mater. 5 (2003) 291-295

38 S. Onaka, Phil. Mag. Lett. 90 (2010) 633-639

39 S. Shrivastava, C. Ghosh, J.J. Jonas, Phil. Mag. 92 (2012) 779-786

40 S. Onaka, Phil. Mag. 92 (2012) 2264-2271

41 S. Onaka, Mater. Trans. 53 (2012) 1547-1548

42 J.J. Jonas, C. Ghosh, L.S. Toth, Mater Sci Eng A 607 (2014) 530-535

43 A. P Zhilyaev, T.G. Langdon, 2014 IOP Conf. Ser.: Mater. Sci. Eng. 63012052

44 W.M. Gan, M.Y. Zheng, H. Chang, X.J. Wang, X.G. Qiao, K. Wu, B. Schwebke, H.G.

Brokmeier, J Alloys Compd 470 (2009) 256-262

45 X.Q. Guo, W. Wu, P.D. Wu, H. Qiao, K. An, P.K. Liaw, Scripta Mater, 69 (2013) 319-322

46 W.J. Kim, H.T. Jeong, Mater Trans. 46 (2005) 251-258

47 D.R. Nugmanov, R. K. Islamgaliev, Rev. Adv. Mater. Sci. 31 (2012) 157-162

48 A. Styczynski, Ch. Hartig, J. Bohlen, D. Letzig. Scripta Mater 50 (2004) 943-947.

49 Y. Huang, R.B. Figueiredo, T. Baudin, A.L. Helbert, F. Brisset, T.G. Langdon. Mater

Res. 16 (2013) 577-585

50 D.K. Xu, E.H. Han, Scripta Mater, 69 (2013) 702-705

51 S.B. Yi, C.H.J. Davies, H.G. Brokmeier, R.E. Bolmaro, K.U. Kainer, J. Homeyer, Acta Mater, 54 (2006) 549-562

52 K. Edalati, Z. Horita, Acta Mater 59 (2011) 6831-6836

53 M. A. W. Lowden, W. B. Hutchinson, Metall Trans A, 64 (1975) 441-448

54 M. Schwartz, S. K. Nash, R. Zeman, Trans Metall Soc AlME, 221 (1961) 554-560

55 E. Kelly, W.F. Hosford, Trans.Metall. Soc. AIME 242 (1968) 5-13.

56 T. Obara, H. Yoshinga, S. Morozumi, Acta Metall, 21 (1973) 845-853

57 S. Ando, H. Tonda, Mater Sci Forum 350-351 (2000) 43-48

58 J. Koike, T Kobayashi, T Mukai, H Watanabe, M Suzuki, K Maruyama, K Higashi,

Acta Mater 51 (2003) 2055-2065

59 S.R. Agnew, Ö. Duygulu, Int J Plast, 21 (2005) 1161-1193

60 F.E. Hauser, P.R. Landon, I.E. Dorn,Trans. ASM 50 (1958) 856-883

61 H. Van Swygenhoven, P.M. Derlet, A.G. Froseth, Nat Mater 3 (2004) 399-403.

62 S.R. Agnew, in: C. Bettles and M. Barnett (Eds.), Advances in wrought magnesium alloys, Woudhead publishing, Cambridge, 2012, pp 63-105

63 M.R. Barnett, in: C. Bettles and M. Barnett (Eds.), Advances in wrought magnesium alloys, Woudhead publishing , Cambridge, 2012, pp 105-144

64 M.R. Barnett, Z. Keshavarz, A.G. Beer, D. Atwell, Acta Mater 52 (2004) 5093-5103 
65 I.J. Beyerlein, C.N. Tomé, Proc R Soc A: Math Phys Eng Sci, 466 (2010) 2517-2544 66 M.R. Barnett, Scripta Mater 59 (2008) 696-698 